\title{
Long-term outcome among men with conservatively treated localised prostate cancer
}

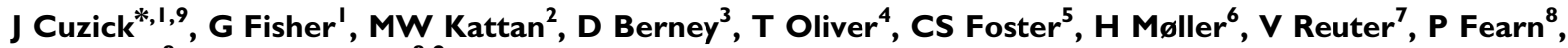 J Eastham ${ }^{8}$ and $P$ Scardino ${ }^{8,9}$ on behalf of the Transatlantic Prostate Group}

'Cancer Research UK Centre for Epidemiology, Mathematics and Statistics, Wolfson Institute of Preventive Medicine, St Bartholomew's Medical School, Queen Mary, University of London, Charterhouse Square, London ECIM 6BQ, UK; ${ }^{2}$ Department of Quantitative Health Sciences, The Cleveland Clinic Foundation, Cleveland, OH 44 195, USA; ${ }^{3}$ Department of Histopathology, St Bartholomew's Hospital, London EI 2ES, UK; ${ }^{4}$ Department of Medical Oncology, St Bartholomew's Hospital, London ECIA 7BE, UK; ${ }^{5}$ Department of Cellular Pathology and Molecular Genetics, Liverpool University Hospital, Liverpool LI 3GA, UK; ${ }^{6}$ King's College, Thames Cancer Registry, London SEI 3QD, UK; ${ }^{7}$ Department of Pathology, Memorial Sloan Kettering Cancer Center, New York, NY I002 I, USA; ${ }^{8}$ Department of Urology, Memorial Sloan-Kettering Cancer Center, 1275 York Avenue, New York, NY I002I, USA

Optimal management of clinically localised prostate cancer presents unique challenges, because of its highly variable and often indolent natural history. There is an urgent need to predict more accurately its natural history, in order to avoid unnecessary treatment. Medical records of men diagnosed with clinically localised prostate cancer, in the UK, between 1990 and 1996 were reviewed to identify those who were conservatively treated, under age 76 years at the time of pathological diagnosis and had a baseline prostate-specific antigen (PSA) measurement. Diagnostic biopsy specimens were centrally reviewed to assign primary and secondary Gleason grades. The primary end point was death from prostate cancer and multivariate models were constructed to determine its best predictors. A total of 2333 eligible patients were identified. The most important prognostic factors were Gleason score and baseline PSA level. These factors were largely independent and together, contributed substantially more predictive power than either one alone. Clinical stage and extent of disease determined, either from needle biopsy or transurethral resection of the prostate (TURP) chips, provided some additional prognostic information. In conclusion, a model using Gleason score and PSA level identified three subgroups comprising 17, 50, and 33\% of the cohort with a 10-year prostate cancer specific mortality of $<10$, $10-$ 30 , and $>30 \%$, respectively. This classification is a substantial improvement on previous ones using only Gleason score, but better markers are needed to predict survival more accurately in the intermediate group of patients.

British Journal of Cancer (2006) 95, I | 86- | |94. doi: I0.1038/sj.bjc.66034 I I www.bjcancer.com

(C) 2006 Cancer Research UK

Keywords: localised prostate cancer; prognostic factors

The natural history of prostate cancer is highly variable and difficult to predict. Over treatment of asymptomatic patients is a serious problem leading to substantial morbidity. Introduction of prostate-specific antigen (PSA) testing in some countries has exacerbated this problem, leading to a much higher reported incidence rate, but having little influence on mortality rates (Evans and Møller, 2003). In the United States, where PSA testing has been common, the incidence to mortality ratio is about 7.6. Conversely, in the United Kingdom, where PSA testing is not performed routinely, the ratio is approximately 2.5. Autopsy series have confirmed that histologically proven prostate cancer can be identified in approximately $40 \%$ of men over 50 years of age who die of other causes (Breslow et al, 1977; Sakr et al, 1994). This is about four times higher than the lifetime risk for American men to be diagnosed with prostate cancer (approximately 11\%), indicating that more intensive screening is likely to uncover even

\footnotetext{
*Correspondence: Professor J Cuzick; E-mail: jack.cuzick@cancer.org.uk

${ }^{9}$ Principal investigators.

Received 15 May 2006; revised 10 August 2006; accepted 10 August 2006
}

more indolent disease. This had led many countries, in particular the United Kingdom, to endorse a more conservative approach to disease detection and management. In the UK, PSA screening is not endorsed by the health service (although it is available on request) and radical prostatectomy or radiation therapy is not common practice. However, this approach is not without problems, since a substantial proportion of men develop progressive disease from which they ultimately die. Furthermore, conservative management can lead to considerable anxiety, especially when the clinical outcome is so uncertain.

Several studies have attempted to document the long-term risk of metastases and death from prostate cancer in men with conservatively managed, clinically localised cancers (Chodak et al, 1994; Albertsen et al, 1995, 1998, 2005a; Adolfsson et al, 1997; Holmberg et al, 2002; Johansson et al, 2004; Bill-Axelson et al, 2005). Two of these (Albertsen et al, 1998; Johansson et al, 2004) estimated outcome based on histological tumour grade, but did not include either clinical stage or initial serum PSA level and reviewed Gleason grades. The former (Albertsen et al, 1998) reported long-term outcomes for 767 men aged 55-74 years at diagnosis with conservatively treated clinically localised prostate cancer. Men with cancers that have Gleason scores of 2-4, 5, 6, 7, 
and $8-10$ had a 4-7, 6-11, 18-30, 42-70, and $60-87 \%$ chance, respectively, of dying from prostate cancer within 15 years of diagnosis, depending on their age at diagnosis. Their revised estimate of 20-year survival (Albertsen et al, 2005a) indicated that annual mortality rates remained stable after 15 years from diagnosis. In contrast to these findings, the latter study (Johansson et al, 2004) reported an approximately three-fold increase in the rate of progression and prostate cancer-specific mortality rate after 15 years among their small cohort of 223 patients.

The first randomised trial of primary treatment with curative intent for men with localised prostate cancer was reported by Holmberg et al (2002) and later by Bill-Axelson et al (2005). This trial included 695 men, with clinically localised prostate cancer, randomised to either radical prostatectomy or no initial treatment with systemic treatment deferred until the development of symptomatic progression. The authors found a reduced risk of progression and death from prostate cancer in the radically treated men, but concluded that the disease-specific benefits of radical prostatectomy must be weighed carefully against the potential impact that surgery can have on quality of life. Other studies (Chodak et al, 1994; Albertsen et al, 1995, 1998, 2005a; Adolfsson et al, 1997; Holmberg et al, 2002) have concluded that watchful waiting or no initial treatment with treatment delayed until the development of symptomatic metastatic disease remains a viable treatment option.

These studies emphasise the varied natural history of clinically localised prostate cancer, especially for the intermediate risk prostate cancers with Gleason score 6-7.

A basic tenet of an effective screening programme is that the natural history of the disease should be understood well and that early detection can have an important impact on outcome. Neither of these requirements has been satisfied for prostate screening. This study was performed to evaluate the utility of whether other factors such as PSA, clinical stage and extent of disease could provide useful prognostic information in addition to histological grade.

\section{MATERIALS AND METHODS}

\section{Study population and data collection}

This was a population-based study in which potential cases were identified from six cancer registries in Great Britain. Within each region, collaborating hospitals were sought and cases from these hospitals were reviewed. National approval was obtained from the Northern Multi-Research Ethics Committee, followed by local ethics committee approval at each of the collaborating hospital trusts (Appendix A).

Men were included in this study if they were under age 76 years at the date of diagnosis and had clinically localised prostate cancer diagnosed by transurethral resection of the prostate (TURP) or needle biopsy. Diagnosis between 1990 and 1996 (inclusively) and a baseline PSA were required.

Patients treated by radical prostatectomy or radiation therapy within 6 months of diagnosis were excluded. In addition, those with objective evidence of metastatic disease (by bone scan, X-ray, radiograph, CT scan, MRI, bone biopsy, lymph node biopsy, pelvic lymph node dissection) or clinical indications of metastatic disease (including pathologic fracture, soft tissue metastases, spinal compression, or bone pain), or a PSA measurement over $100 \mathrm{ng} \mathrm{ml}^{-1}$ at or within 6 months of diagnosis were also excluded. These exclusions were a pragmatic method of focusing the study on patients who were very likely to have truly localised disease at presentation. Men who had hormone therapy prior to diagnostic biopsy were also excluded, because of the influence of hormone treatment on interpreting Gleason grade. We also excluded men who died within 6 months of diagnosis, or had less than 6 months of follow-up.

Registry data had limited utility for eliminating ineligible cases, thus a review of hospital records was necessary to establish eligibility. The review process and selection of cases is summarised in Figure 1.

Registry data collection officers and trained medical staff conducted on-site medical record reviews at each of 51 hospital trusts (Appendix A).

Clinical staging was centrally reviewed and, where unstated in the notes, was assigned, where possible, by an urologist based on the reported findings. In approximately $24 \%$ of cases, no information was available and in a further $16 \%$ of cases, stage could not be assigned. In both circumstances, these cases were designated Tx.

Original histological specimens from the diagnostic procedure (needle biopsy or TURP) were requested, collected, and centrally reviewed by a panel of expert urological pathologists to confirm the diagnosis and, where necessary, to reassign Gleason grades for all the prostate cancers using a conventional interpretation (Deshmukh and Foster, 1997) of the Gleason grading system. Approximately $12 \%$ of requested specimens were missing or unidentifiable in hospital pathology databases. A further $17 \%$ of cases had no Gleason grade assigned for a variety of reasons (Figure 1). Outcomes were determined through medical records and cancer registry data. In January 2005, the cancer registries were queried to obtain the most up-to-date survival data. Date of last follow-up was different for each cancer registry; the earliest was March 2004 and the latest was January 2005. Where available, death certificates for deceased patients were reviewed to verify cause of death. Deaths were divided into two categories, death from prostate cancer and death from other causes, according to standardised World Health Organisation criteria. Patients still alive at last follow-up were censored at that date.

Disease progression (treatment failure) was defined as clinical, histological, or radiographic evidence of metastatic disease (lymph node, bone, or soft tissue); or institution of additional hormone therapy, radiation therapy, surgery, chemotherapy, or death certified to be from prostate cancer.

\section{Statistics}

The primary end point to this study was time to death from prostate cancer. An initial analysis characterised patient status at different follow-up times (death from prostate cancer, death from other causes, alive with progression, alive without progression) in which censoring was done only if alive and progression free at last follow-up. Subsequent analyses of the main end points were performed by proportional hazards models, censoring at the time of death from other causes, or latest follow-up time. All follow-up times commenced at the point of 6 months following diagnosis. The following variables were recorded: Gleason score, all available PSA values, clinical stage, extent of disease (proportion of TURP chips with disease or linear proportion of needle biopsy containing disease), age at diagnosis, method of diagnosis (TURP or needle biopsy), and initial treatment (no initial treatment or early hormone management). Baseline PSA was defined as the last PSA value within 6 months of diagnosis (including pre-diagnostic values), but before initiation of hormone therapy and at least 3 weeks after any biopsy. Patients for which any of these values greater than $100 \mathrm{ng} \mathrm{ml}^{-1}$ were excluded.

Variables were first examined separately and then multivariate models were constructed by a forward stepwise selection method. For the multivariate models, a single linear trend variable across categories was used for assessing the importance of a new variable. If the variable was included, a second variable indicating missing 

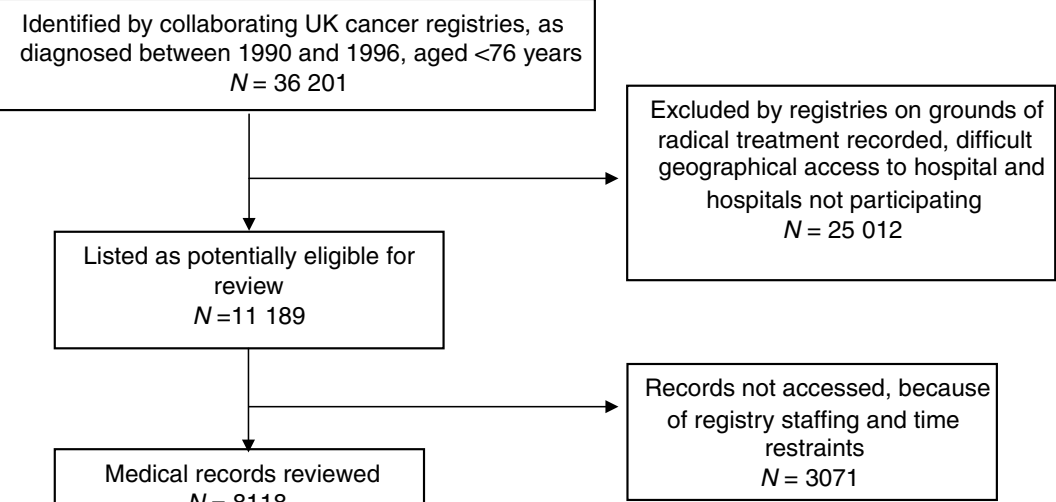

$\begin{array}{lr}\text { Excluded, inorder of exclusion: } & \\ \text { No biopsy record } & 3063 \\ \text { Biopsy date not between } 1990 \text { and } 1996 & 87 \\ \text { Age } \geqslant 76 \text { years } & 78 \\ \text { No baseline PSA } & 1773 \\ \text { Curative surgery within } 6 \text { months } & 148 \\ \text { Radiation therapy within } 6 \text { months } & 214 \\ \text { Metastasis within } 6 \text { months } & 301 \\ \text { Death within } 6 \text { months } & 28 \\ \text { Prior invasive cancer with in } 5 \text { years } & 35 \\ \text { Hormone therapy before biopsy } & 56 \\ \text { Less than } 6 \text { months follow-up data } & 2\end{array}$

\begin{tabular}{|lr|}
\hline & $N(\%)$ \\
Cases not requested & $203(9)$ \\
Excluded on review: & \\
Inknown, missing histology slides & $284(12)$ \\
Histologically negative & $43(2)$ \\
No histology tissue left in block & $135(6)$ \\
Histologically ungradeable Gleason score & $6(<1)$ \\
& $6(<1)$ \\
\hline
\end{tabular}

Cases with reviewed histology and Gleason score

$N=1656$

Figure I Cohort assembly.

(unassigned) data was added before proceeding to examine further variables. This was done to avoid loss of patients when one variable was missing. A predictor was developed using Gleason score and separate categories of PSA to create prognostic groups. All $P$-values are two-sided and $95 \%$ confidence intervals were based on the normal distribution with parameters derived from partial likelihood calculations.

\section{RESULTS}

\section{Cohort assembly}

The process of identification of eligible patients is summarised in Figure 1.

Of 2333 men eligible for evaluation, 1663 were managed by no initial treatment and 670 were managed by early hormone therapy. Overall, the median age at diagnosis was 70.1 years (range $44-76$ years) and the median follow-up was 117 months (range 88-180 months). Most men (80\%) were diagnosed after age 65 years. A competing risk analysis showed that after 10 years of follow-up, $55 \%$ of the men had died, $24 \%$ from prostate cancer and $31 \%$ from other causes and only $22 \%$ were still alive without progression (Figure 2).

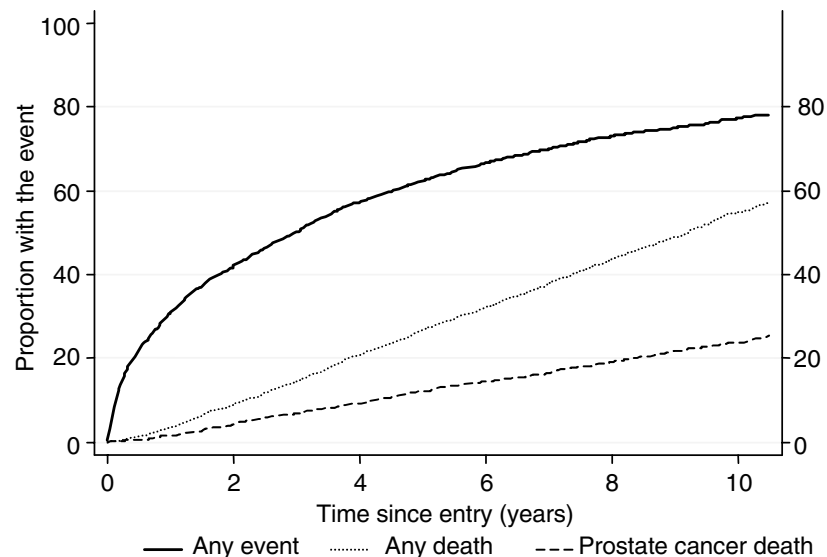

Figure 2 Proportion of patients either dead from prostate cancer, dead from any cause, or dead, progressed or with treatment failure, at different follow-up times.

Early hormone therapy treated patients were diagnosed more recently and had a shorter follow-up time, but the age at diagnosis was similar for both cohorts $(P=0.25)$. Diagnosis was made by 
TURP in 1255 men (54\%), needle biopsy in 1039 men (45\%) and was unspecified in 39 men (1\%). Patients treated early by hormone manipulation had a worse prognosis, even after multivariate adjustment. Consequently, results are also given separately for the two methods of initial management.

The distribution of baseline factors and the univariate risk of death from prostate cancer for these factors are shown in Table 1.
Separate analyses for patients with early hormone therapy and no initial treatment are given in Appendix A (Table A1).

\section{Gleason grade}

Reviewed Gleason scores were available for $71 \%$ of the total cohort, $71 \%$ of those treated by no initial treatment, and $72 \%$ of

Table I Univariate analysis of factors influencing death from prostate cancer in men with conservatively managed clinically localised prostate cancer (total eligible cohort $=2333$ )

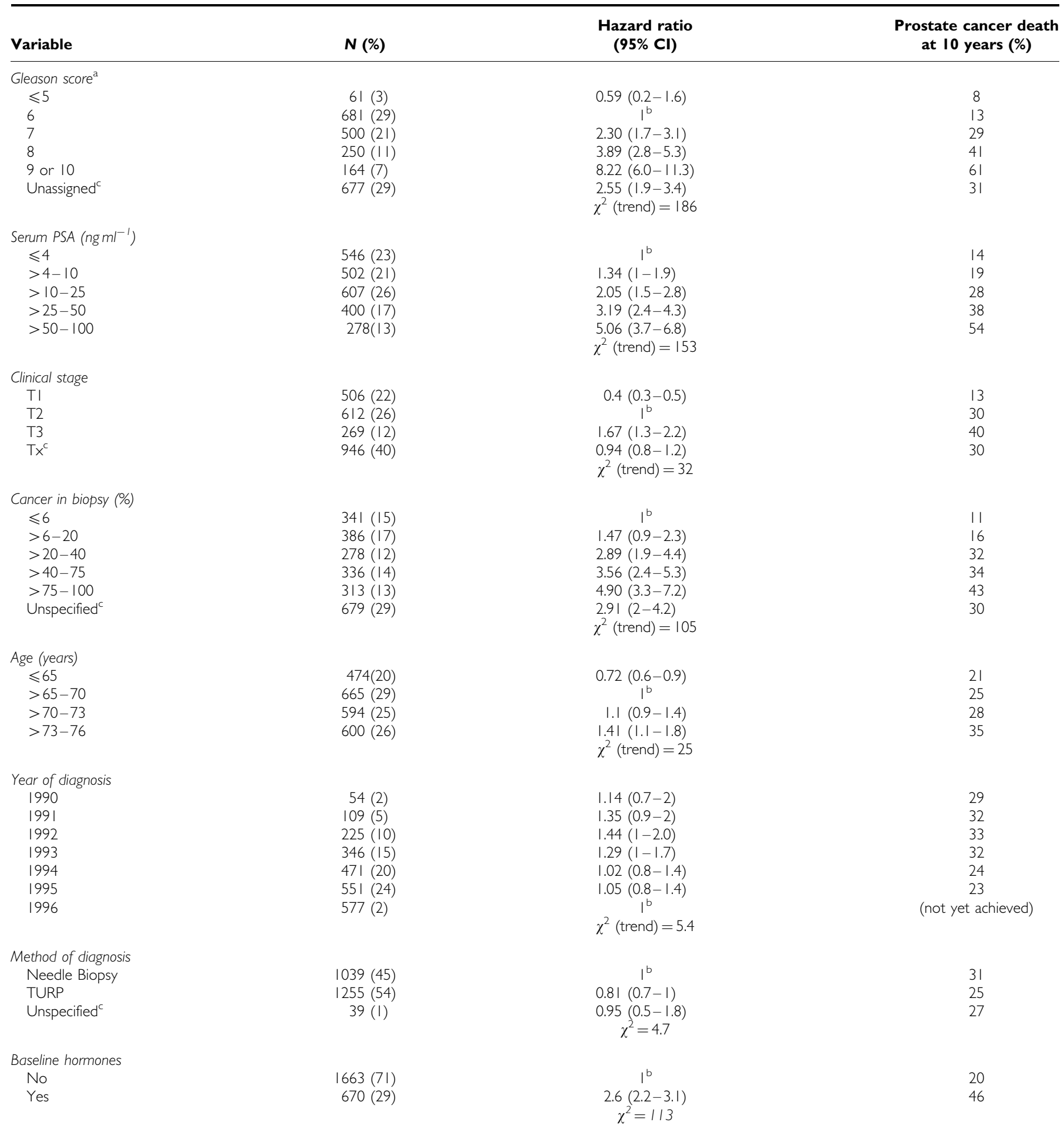

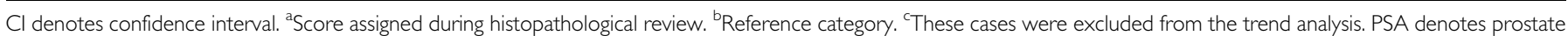
specific antigen. TURP denotes trans urethral resection of the prostate. 
those treated by early hormone therapy. Gleason score had the greatest discriminating power, even though this was based on a subset of the cohort (Table 1). A clear gradation was seen across groups with a $\chi^{2}$ (trend) of 186 , in the total cohort, for prostate cancer death. The predictive power was weaker in patients initially treated by early hormone therapy, but was still stronger than any other variable for this group. Patients, whose histology was not available for review, were similar to the overall group, with a survival curve very similar to those with a Gleason score of 7 . Those with a Gleason score of 4 or 5 had a 10-year prostate cancer survival rate of $92 \%$ compared to $41 \%$ for those with Gleason score 9 or 10 . We further subdivided the Gleason score 7 into $3+4$ and $4+3$, but they behaved similarly (HR 2.17 vs 2.51, 10 years survival 73 vs $68 \%$ respectively).

\section{Baseline PSA}

Baseline PSA values were the second most useful variable and almost as discriminating as Gleason score. The $\chi^{2}$ (trend) was 153 for prostate cancer death. Again, a clear gradient was seen with survival at 10 years, being $86 \%$ for men with PSA values $<4 \mathrm{ng} \mathrm{ml}^{-1}$, but only $46 \%$ for men with values between 50 and $100 \mathrm{ng} \mathrm{ml}^{-1}$. Much of the impact of PSA was independent of Gleason score, as can be seen from the multivariate analysis (Table 2a). Low values were less predictive for patients treated by early hormone management.

\section{Clinical stage and extent of disease}

A total of $1387(60 \%)$ patients had sufficient information available to assign a clinical stage. In univariate analysis, a clear but smaller difference than for Gleason score or baseline PSA was seen. Extent of disease proved to be more useful than clinical stage for both cohorts (Table 1) and retained significance in multivariate models.

\section{Age, method, and year of diagnosis}

Age had a clear effect on non-prostate cancer death as expected. The 10-year death rates from other causes were $18,30,42,47 \%$ for ages $<65,65-70,71-73,74-75$ respectively $\left(\chi^{2}\right.$ (trend) $\left.=104\right)$. An effect was also seen for death from prostate cancer. However, no effect was seen on progression rates (data not

Table 2a Hazard ratios for multivariate model for prostate cancer death based on Gleason score and PSA, in patients having both variables available

\begin{tabular}{|c|c|c|c|}
\hline \multirow[b]{2}{*}{ Variable } & \multicolumn{3}{|c|}{ Prostate cancer death } \\
\hline & $\begin{array}{c}\text { Total } \\
\text { eligible } \\
(N=1656)\end{array}$ & $\begin{array}{l}\text { No initial } \\
\text { treatment } \\
(N=1176)\end{array}$ & $\begin{array}{c}\text { Initial } \\
\text { hormones } \\
(N=480)\end{array}$ \\
\hline \multicolumn{4}{|l|}{ Gleason score } \\
\hline$\leqslant 5$ & 0.67 & 0.63 & 1.50 \\
\hline 6 & $1^{\mathrm{b}}$ & $1^{\mathrm{b}}$ & $1^{b}$ \\
\hline $7(3+4,4+3)$ & 1.77 & 1.88 & 1.13 \\
\hline $8(3+5,4+4,5+3)$ & 3.00 & 3.26 & 1.79 \\
\hline 9 or 10 & 5.96 & 6.77 & 3.56 \\
\hline \multicolumn{4}{|l|}{ Serum PSA $\left(n g m l^{-1}\right)$} \\
\hline$\leqslant 4$ & $1^{\mathrm{b}}$ & $1^{b}$ & $1^{b}$ \\
\hline$>4-10$ & 1.06 & 0.81 & 1.05 \\
\hline$>10-25$ & 1.42 & 1.60 & 0.65 \\
\hline$>25-50$ & 2.23 & 1.67 & 1.73 \\
\hline$>50-100$ & 2.62 & 1.92 & 1.67 \\
\hline
\end{tabular}

${ }^{\mathrm{a} S}$ core assigned during histopathological review. ${ }^{\mathrm{b}}$ Reference category. shown), suggesting this may represent confounding with other established risk factors, or misclassification of cause of death in the elderly.

Method of diagnosis (TURP or needle biopsy) and year of diagnosis had little impact on outcome.

\section{Multivariate model}

A forward stepwise selection multivariate model was developed. The variables were entered in the following order and their relative strengths indicated by the increment in $\chi^{2}\left(\Delta \chi^{2}\right)$ : Gleason Grade (186.4), PSA (84), age (15.2), percentage cancer in the biopsy (9.8), clinical stage (8.0), and year of diagnosis (2.8). Full details are given in Appendix A (Table A2 (a)). Separate models for no initial treatment and early hormone therapy are provided also in Appendix A (Table A2 (b) and (c)).

The most predictive variable was Gleason score, followed by baseline PSA, age, extent of disease, and clinical stage. Method of initial treatment was also important, even after adjustment for other factors, reflecting an additional selection of poor risk patients among those given early hormone therapy.

A multivariate model for prostate cancer death based only on different levels of Gleason score and baseline PSA is shown in Table $2 \mathrm{a}$ and $\mathrm{b}$.

This was clearly better than the univariate models. Almost all of the information was contained in Gleason score and baseline PSA. With these two variables we were able to identify $17 \%$ of the cohort for which the Gleason score was $\leqslant 5$ and $\mathrm{PSA}<25 \mathrm{ng} \mathrm{ml}^{-1}$ or the Gleason score was 6 and PSA $\leqslant 4 \mathrm{ng} \mathrm{ml}^{-1}$ where prostate cancer mortality at 10 years was less than $10 \%$ and $33 \%$ of the cohort with Gleason score 7 and PSA $>25 \mathrm{ng} \mathrm{ml}^{-1}$, or Gleason score 8 and PSA $>10 \mathrm{ng} \mathrm{ml}^{-1}$, or Gleason score $\geqslant 9$ where prostate cancer mortality at 10 years was greater than $30 \%$. This last group could be further split into a very poor prognostic group (Gleason score $\geqslant 9$ and PSA $>25 \mathrm{ng} \mathrm{m}^{-1}$ ) comprising $5 \%$ of men with a 10 -year prostate cancer mortality greater than $75 \%$ (Table 2b).

The relative importance of death from prostate cancer $v s$ other causes over the first 10 years of follow-up for different prognostic groups is shown (Figure 3) separately for men aged 70 years or less and men aged more than 70 years, at diagnosis.

\section{DISCUSSION}

Prostate cancer is currently the second leading cause of cancer death among men in both the UK and USA. However, approximately half the men diagnosed with this disease do not die from it, even in the absence of radical treatment (Satariano

Table 2b Predicted prostate cancer specific survival at 10 years based on baseline PSA and Gleason score, in men with clinically localised disease

\begin{tabular}{|c|c|c|c|c|c|}
\hline \multirow[b]{2}{*}{ PSA $\left(n g\right.$ ml $\left.^{-1}\right)$} & \multicolumn{5}{|c|}{ Gleason score } \\
\hline & 5 or less & 6 & 7 & 8 & 9 or 10 \\
\hline$\leqslant 4$ & $93(2)$ & $90(14)$ & $83(4.1)$ & $72(2.2)$ & $53(0.9)$ \\
\hline$>4-10$ & $93(1)$ & $89(11)$ & $82(4.7)$ & $71(1.9)$ & $51(1.3)$ \\
\hline$>10-25$ & $90(0.4)$ & $86(10.9)$ & $76(8.9)$ & $63(4.2)$ & $40(2.5)$ \\
\hline$>25-50$ & $85(0.2)$ & $79(3.7)$ & $65(7.3)$ & $48(4)$ & $24(2.5)$ \\
\hline$>50-100$ & $83(0.1)$ & $75(1.6)$ & $61(5.2)$ & $43(2.8)$ & $19(2.6)$ \\
\hline
\end{tabular}

Three groups are identified with 10 year survival of $\geqslant 90,70-89$, and $\leqslant 70 \%$ The analysis is based on all patients for whom neither variable was missing $(n=1656)$. Numbers in parentheses indicate the percentage of total cohort in this group. 

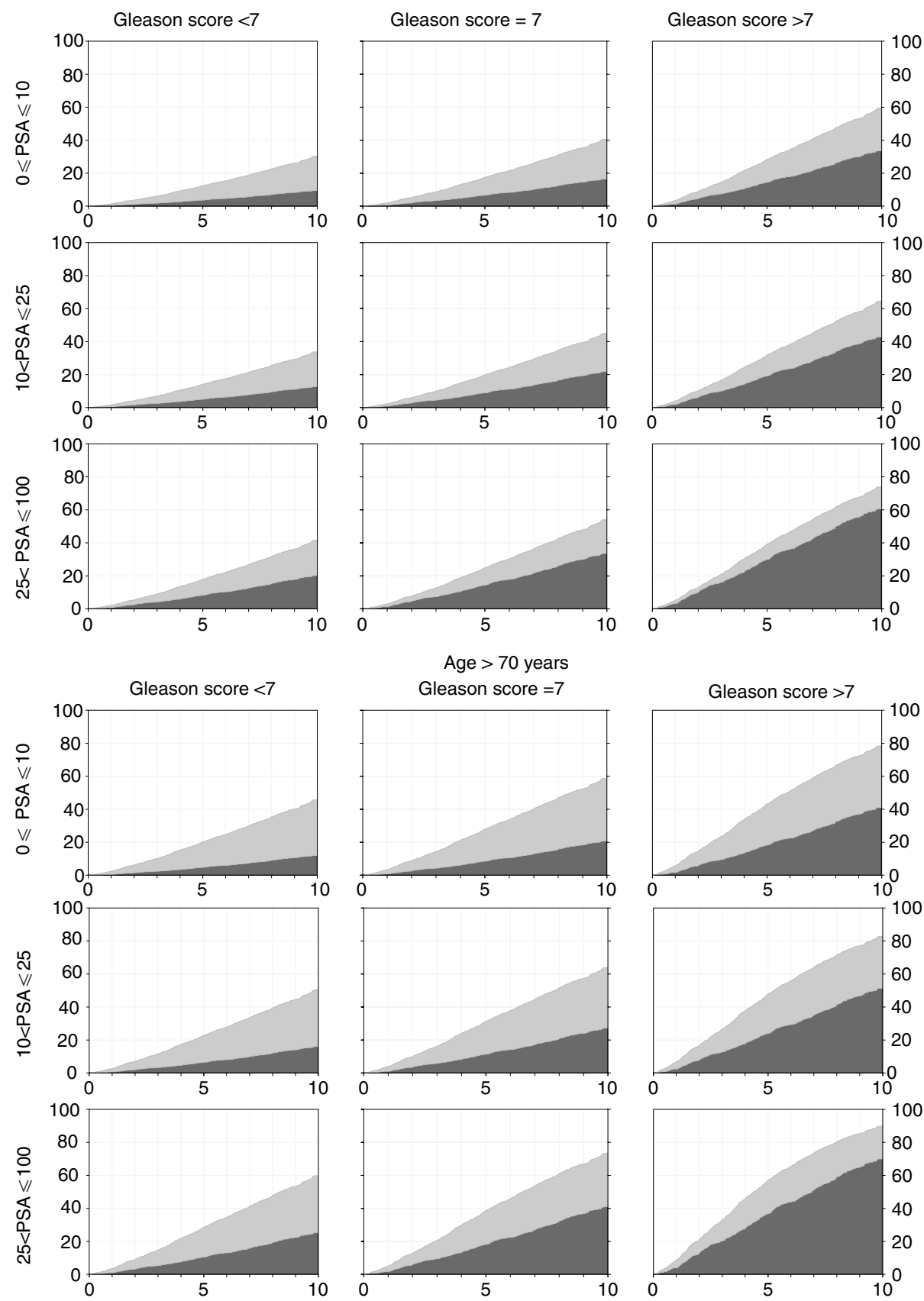

Figure 3 Proportion of patients dead from prostate cancer (dark grey), dead from other causes (light grey), at different follow-up times up to 10 years, according to baseline PSA and Gleason score, separately for patients aged 70 years or less at diagnosis and patients aged more than 70 years at diagnosis.

et al, 1998). This makes counselling patients about management difficult. Recent results from the Scandinavian Prostate Cancer Study Group (Bill-Axelson et al, 2005) demonstrate a reduction in metastatic disease and prostate cancer-specific mortality for radical prostatectomy compared to watchful waiting, but the gains are small and it is not clear which men will benefit in this. Our data incorporate informative prognostic parameters not analysed in previous studies on conservatively treated men. In agreement with Albertsen et al (1995) and Johansson et al (2004), we found Gleason score to be an important determinant of cancer-specific mortality. In addition, we found baseline PSA level and to a lesser extent clinical stage and extent of disease added further predictive value. Importantly, the information contained in PSA levels was largely independent of that available from Gleason score and vice versa, so that using both variables produced a simple classification into three groups with very different outcomes.

Compared to previous studies, there are several reasons why our findings are more applicable to a man diagnosed with localised prostate cancer in the modern era. Firstly, the incorporation of PSA augments the prognostic stratification by histological grading alone. Secondly, the Gleason scoring in our study more accurately reflects current pathological grading methods. Multiple investigators have documented an upward shift in Gleason score over time (Kondylis et al, 2003; Albertsen et al, 2005b) - not representative of a change in biology, but of pathologists today being more likely to assign higher Gleason scores. Albertsen et al (2005a,b) assigned 
Gleason grades in 1990-1992 and 33\% of patients had a Gleason score of 5 or less compared to our study where only $3 \%$ patients had this classification. Thirdly, in Albertsen's cohort, $24 \%$ of patients had a Charlson Index (Charlson et al, 1987) of two or greater, considered to be 'significant co morbidity'. Consequently, the cohort represents probably a high proportion of patients not medically suitable, or patients deciding not to opt for primary curative therapy. Since conservative management was used for a much broader group of patients in the United Kingdom, our population-based cohort may be a more representative one for men faced with the choice of conservative $v s$ curative-intent therapy. While $54 \%$ of our patients were diagnosed by TURP, which is much higher than would be found in a contemporary series, this did not have an impact on outcomes, PSA levels were on average also higher than for current series, but there were sufficient numbers of patients in all groups to obtain reliable prognostic information across the full spectrum of values. Lastly, our cohort is more than three times the size of previous studies, providing more accurate estimates of risk and greater statistical power.

Kattan et al (1998) found clinical stage, PSA, and Gleason grade to be parameters predictive of PSA recurrence for men treated by radical prostatectomy. In our study, clinical stage provided only a small additional amount of information on prostate cancer death. However, our information on clinical stage was unavailable for $40 \%$ of the cohort, and were recorded, was limited and based on a retrospective review of clinical notes from a variety of institutions. It is possible that carefully collected and complete prospective information would prove to be more prognostic. This is in contrast to the data on PSA that was $100 \%$ complete and centrally reviewed Gleason Grade, which was available for $71 \%$ of the cohort. Age was a strong predictor of death from causes other than prostate cancer, and provided some additional information on prostate cancer mortality. However, it did not predict progression, and its effect on prostate cancer mortality may reflect misclassification of cause of death in these elderly men.

Our analyses identified $33 \%$ of men with poor 10 -year cancerspecific mortality ( $>30 \%$ ), where no initial treatment is not a good option, especially when the risk of death from other causes is low. We also identified a group comprising $17 \%$ of men where the 10 -year cancer-specific survival was very good ( $>90 \%)$. Long follow-up will be needed to see if these men remain at low risk of disease-related mortality, since it is not clear if mortality rate trends will plateau or continue to increase. In the Swedish (Johansson et al, 2004) cohort, cancer-specific mortality rates increased during years 15-20 following diagnosis relative to the initial 15 years, whereas Albertsen et al (2005a) found annual cancer-specific mortality rates to be unchanged after 15 years.

In our study, approximately $50 \%$ of patients have what may be considered an intermediate prognosis $(10-30 \% 10$-year cancerspecific mortality), where better markers of disease progression are needed. This applies especially to the $11 \%$ of men with Gleason score 6 and PSA level $4-10 \mathrm{ng} \mathrm{ml}^{-1}$, many of whom undoubtedly have a very good prognosis. Currently, we are collecting all available tumour blocks from the cohort to construct tissue microarrays. It is hoped that identification of new markers with altered DNA or protein expression in prostate cancer will help to highlight disease destined to be clinically relevant, especially for this intermediate group.

In conclusion, we have confirmed Gleason score as an important prognostic factor for men with conservatively treated localised prostate cancer and are the first to include PSA at diagnosis into the prognostic model for these patients. While providing valuable information for men considering or choosing conservative therapy, our study has also emphasised the urgent need to identify better markers of tumour behaviour to assist in formulating appropriate management of individual men with prostate cancer.

\section{ACKNOWLEDGEMENTS}

We gratefully acknowledge support from Cancer Research UK, The Orchid Appeal, National Institutes of Health (SPORE) and the Koch Foundation. We also thank investigators and staff in the cancer registries and participating hospitals (Appendix A) for their support.

Funding bodies had no involvement in the design and conduct of the study, or in collection management, analysis and interpretation of the data, or in preparation, review or approval of the manuscript.

\section{REFERENCES}

Adolfsson J, Steineck G, Hedlund P-O (1997) Deferred treatment of clinically localized low-grade prostate cancer: actual 10-year and projected 15-year follow-up of the Karolinska series. Urology 50: $722-726$

Albertsen PC, Fryback DG, Storer BE, Kolon TF, Fine J (1995) Long-term survival among men with conservatively treated localized prostate cancer. JAMA 274: 626-631

Albertsen PC, Hanley JA, Barrows GH, Penson DF, Kowalczyk PD, Sanders MM, Fine J (2005a) Cancer and the Will Rogers phenomenon. J Natl Cancer Inst 97: 1248 - 1253

Albertsen P, Hanley JA, Fine J (2005b) 20-year outcomes following conservative management of clinically localized prostate cancer. JAMA 293: $2095-2101$

Albertsen PC, Hanley JA, Gleason DF, Barry MJ (1998) Competing risk analysis of men aged 55 to 74 years at diagnosis managed conservatively for clinically localized prostate cancer. JAMA 280: 975-980

Bill-Axelson A, Holmberg L, Ruutu M, Haggman M, Andersson SO, Bratell S, Spangberg A, Busch C, Nordling S, Garmo H, Palmgren J, Adami HO, Norlen BJ, Johansson JE, Scandinavian Prostate Cancer Group Study No. 4 (2005) Radical prostatectomy versus watchful waiting in early prostate cancer. N Engl J Med 352: 1977 - 1984

Breslow N, Chan CW, Dhom G, Drury RA, Franks LM, Gellei B, Lee YS, Lundberg S, Sparke B, Sternby NH, Tulinius H (1977) Latent carcinoma of prostate at autopsy in seven areas. The International Agency for Research on Cancer, Lyons, France. Int $J$ Cancer 20: $680-688$
Charlson ME, Pompei P, Ales KL, MacKenzie CR (1987) A new method of classifying prognostic comorbidity in longitudinal studies: development and validation. J Chronic Dis. 40: 373-383

Chodak GW, Thisted RA, Gerber GS, Johansson JE, Adolfsson J, Jones GW, Chisholm GD, Moskovitz B, Livne PM, Warner J (1994) Results of conservative management of clinically localized prostate cancer. $N$ Engl J Med 330: $242-248$

Deshmukh N, Foster CS (1997) Grading prostate cancer. In Pathology of the Prostate Foster CS, Bostwick DG (eds) pp 191-227. Philadelphia: WB Saunders

Evans MS, Møller H (2003) Recent trends in prostate cancer incidence and mortality in Southeast England. Eur Urol 43: 337-341

Holmberg L, Bill-Axelson A, Helgesen F, Salo JO, Folmerz P, Haggman M, Andersson SO, Spangberg A, Busch C, Nordling S, Palmgren J, Adami HO, Johansson JE, Norlen BJ, Scandinavian Prostatic Cancer Group Study Number (2002) A randomized trial comparing radical prostatectomy with watchful waiting in early prostate cancer. $N$ Engl J Med 347: $781-789$

Johansson JE, Andren O, Andersson SO, Dickman PW, Holmberg L, Magnuson A, Adami HO (2004) Natural history of early, localized prostate cancer. JAMA 291: 2713-2719

Kattan MW, Eastham JA, Stapleton AMF, Wheeler TM, Scardino PT (1998) A preoperative nomogram for disease recurrence following radical prostatectomy for prostate cancer. J Natl Cancer Inst 90: $766-771$ 
Kondylis FI, Moriarty RP, Bostwick D, Schellhammer PF (2003) Prostate cancer grade assignment: the effect of chronological, interpretive and translation bias. J Urol 170: $1189-1193$

Sakr WA, Grignon DJ, Crissman JD, Heilbrun LK, Cassin BJ, Pontes JJ, Haas GP (1994) High grade prostatic intraepithelial neoplasia (HGPIN)

\section{Appendix A}

Members of the Transatlantic Prostate Group included listed authors and investigators designated by an asterisk.

Table Al Univariate analysis of factors influencing death from prostate cancer in men with clinically localised prostate cancer, (a) and given no initial treatment: $N=1663$ and (b) initially treated with hormones: $N=670$

\begin{tabular}{llll}
\hline Variable & $N(\%)$ & $\begin{array}{l}\text { Hazard ratio } \\
(95 \% \mathrm{Cl})\end{array}$ & $\begin{array}{l}\text { Prostate cancer death } \\
\text { at } 10 \text { years }(\%)\end{array}$ \\
\hline
\end{tabular}

(a)

Gleason score ${ }^{\mathrm{a}}$

$\begin{array}{lcc}\leqslant 5 & 57(3) & 0.59(0.2-1.9) \\ 6 & 589(35) & 1^{\mathrm{b}} \\ 7 & 313(19) & 2.24(1.5-3.3) \\ 8 & 136(8) & 3.84(2.5-5.9) \\ 9 \text { or } 10 & 81(5) & 8.64(5.7-13.2) \\ \text { Unassigned }^{c} & 487(29) & 2.39(1.7-3.4) \\ & & \left.\chi^{2} \text { (trend }\right)=101\end{array}$

Serum PSA $\left(n g m l^{-1}\right)$

$\begin{array}{lcc}\leqslant 4 & 513(31) & 1^{\mathrm{b}} \\ >4-10 & 416(25) & 1.14(0.8-1.7) \\ >10-25 & 432(26) & 2.13(1.5-3) \\ >25-50 & 212(13) & 2.64(1.8-3.9) \\ >50-100 & 90(5) & 4.1(2.6-6.3) \\ & & \chi^{2} \text { (trend) }=56\end{array}$

$\begin{array}{ccc}\text { Clinical stage } & & \\ \mathrm{T} 1 & 435(26) & 0.42(0.3-0.6) \\ \mathrm{T} 2 & 395(24) & 1^{\mathrm{b}} \\ \mathrm{T} 3 & 126(8) & 1.69(1.1-2.5) \\ \mathrm{Tx}^{c} & 707(43) & 1.02(0.8-1.4) \\ & & \left.\chi^{2} \text { (trend }\right)=21\end{array}$

$\begin{array}{ccc}\text { Cancer in biopsy (\%) } & & \\ \leqslant 6 & 315(19) & \left.\right|^{\mathrm{b}} \\ >6-20 & 308(19) & 1.16(0.7-2) \\ >20-40 & 196(12) & 2.75(1.7-4.5) \\ >40-75 & 202(12) & 3.73(2.3-6) \\ >75-100 & 156(9) & 4.3(2.6-7) \\ \text { Unspecified }^{c} & 486(29) & 2.58(1.7-4) \\ & & \chi^{2}=59\end{array}$

Age (years)

$\leqslant 65$

$>65-70$

$>70-73$

$>73-76$

$$
\begin{array}{cc}
357(2 \mathrm{I}) & 0.7(0.5-1) \\
466(28) & 1^{\mathrm{b}} \\
417(25) & 1.23(0.9-1.7) \\
423(25) & 1.6(1.2-2.2) \\
& \left.\chi^{2} \text { (trend }\right)=23
\end{array}
$$

6
10
23
38
53
24

Year of diagnosis

$\begin{array}{lcc}1990 & 46(3) & 1.68(0.9-3.2) \\ 1991 & 86(5) & 1.73(1.1-2.8) \\ 1992 & 168(10) & 1.71(1.1-2.6) \\ 1993 & 266(16) & 1.27(0.8-1.9) \\ 1994 & 344(21) & 1.1(0.7-1.7) \\ 1995 & 370(22) & 0.97(0.6-1.5) \\ 1996 & 383(23) & 1^{b} \\ & & \chi^{2} \text { (trend) }=11\end{array}$

Method of diagnosis Needle biopsy TURP

Unspecified $^{c}$ and prostatic adenocarcinoma between the ages of 20-69: an autopsy study of 249 cases. In vivo 8: $439-443$

Satariano WA, Ragland KE, Van Den Eeden SK (1998) Cause of death in men diagnosed with prostate cancer. Cancer 83: $1180-$ 1188

Table AI (Continued)

\begin{tabular}{llll}
\hline Variable & $N(\%)$ & $\begin{array}{l}\text { Hazard ratio } \\
(95 \% \mathrm{Cl})\end{array}$ & $\begin{array}{l}\text { Prostate cancer death } \\
\text { at } 10 \text { years }(\%)\end{array}$
\end{tabular}

(b) Gleason score reviewed ${ }^{\mathrm{a}}$

$\begin{array}{lcc}\leqslant 5 & 4(1) & 1.30(0.2-9.7) \\ 6 & 92(14) & 1^{\mathrm{b}} \\ 7 & 187(28) & 1.28(0.8-2.1) \\ 8 & 114(17) & 1.92(1.1-3.2) \\ 9 \text { or } 10 & 83(12) & 3.82(2.3-6.4) \\ \text { Unassigned }^{c} & 190(28) & 1.78(1.1-2.9) \\ & & \chi^{2}(\text { trend })=33\end{array}$

-
39
40
46
68
48

$$
\text { Serum PSA }\left(n g m l^{-1}\right)
$$

$\leqslant 4$
$>4-10$
$>10-25$
$>25-50$
$>50-100$

$$
\begin{array}{cc}
33(5) & \left.\right|^{\mathrm{b}} \\
86(13) & 1.03(0.5-2.2) \\
175(26) & 0.79(0.4-1.6) \\
188(28) & 1.42(0.7-2.8) \\
188(28) & 1.95(1-3.9) \\
& \chi^{2} \text { (trend) }=20
\end{array}
$$

Clinical stage
TI
T2
T3
Tx

$$
\begin{array}{r}
71(11) \\
217(32) \\
143(21)
\end{array}
$$

$239(36)$

$$
\begin{gathered}
0.7(0.4-\mid .2) \\
\left.\right|^{\mathrm{b}} \\
1.32(0.9-1.9) \\
1.04(0.8-1.4) \\
\chi^{2}(\text { trend })=2
\end{gathered}
$$

36
40
32
48
62

Cancer in biopsy (\%)

$\leqslant 6$
$>6-20$
$>20-40$
$>40-75$
$>75-100$
Unspecified $^{c}$

\section{$26(4)$}

$78(12)$

$82(12)$

$134(20)$

$157(23)$

$193(29)$

$$
\begin{gathered}
\left.\right|^{b} \\
1.13(0.5-2.6) \\
1.41(0.6-3.2) \\
1.28(0.6-2.9) \\
1.87(0.9-4.1) \\
1.56(0.7-3.4) \\
\chi^{2}=5.8
\end{gathered}
$$

$$
\begin{aligned}
& \text { Age (years) } \\
& \quad \leqslant 65 \\
& >65-70 \\
& >70-73 \\
& >73-76
\end{aligned}
$$

$117(18)$
$199(30)$
$177(26)$
$177(26)$

$0.88(0.6-1.3)$
$\left.\right|^{b}$
$1.0(0.7-1.4)$
$1.24(0.9-1.7)$
$\chi^{2}$ (trend) $=2.8$

42

Year of diagnosis

$\begin{array}{lccc}1990 & 8(1) & 0.65(0.2-2.1) & 25 \\ 1991 & 23(3) & 1.18(0.6-2.3) & 40 \\ 1992 & 57(9) & 1.39(0.9-2.3) & 53 \\ 1993 & 80(12) & 1.75(1.2-2.6) & 63 \\ 1994 & 127(19) & 1.08(0.7-1.6) & 41 \\ 1995 & 181(27) & 1.16(0.8-1.7) & 40 \\ 1996 & 194(29) & 1^{\text {b }} & \text { (not yet achieved) }\end{array}$

Method of diagnosis

$\begin{array}{lccc}\text { Needle biopsy } & 428(64) & \left.\right|^{\mathrm{b}} & 42 \\ \text { TURP }^{\mathrm{b}} & 232(35) & 1.37(1.1-1.8) & 52 \\ \text { Unspecified }^{c} & 10(1) & 1.26(0.5-3.1) & 50 \\ & & \chi^{2}=4.8 & \end{array}$

Cl denotes confidence interval. ${ }^{a}$ Score assigned during histopathological review. ${ }^{b}$ Reference category. 'These cases were excluded from the trend analysis.[2] PSA denotes prostate-specific antigen. TURP denotes trans urethral resection of the prostate. 
Table A2 Multivariate model for prostate cancer death based on Gleason Grade $(G)$, PSA (P), age (A), percentage cancer in biopsy $(C)$, clinical stage ( $T$ ), year $(Y)$ and $(a)$ initial hormone treatment $(H),(b)$ In patients with no initial treatment, and (c) Patients with initial treatment by early hormone therapy

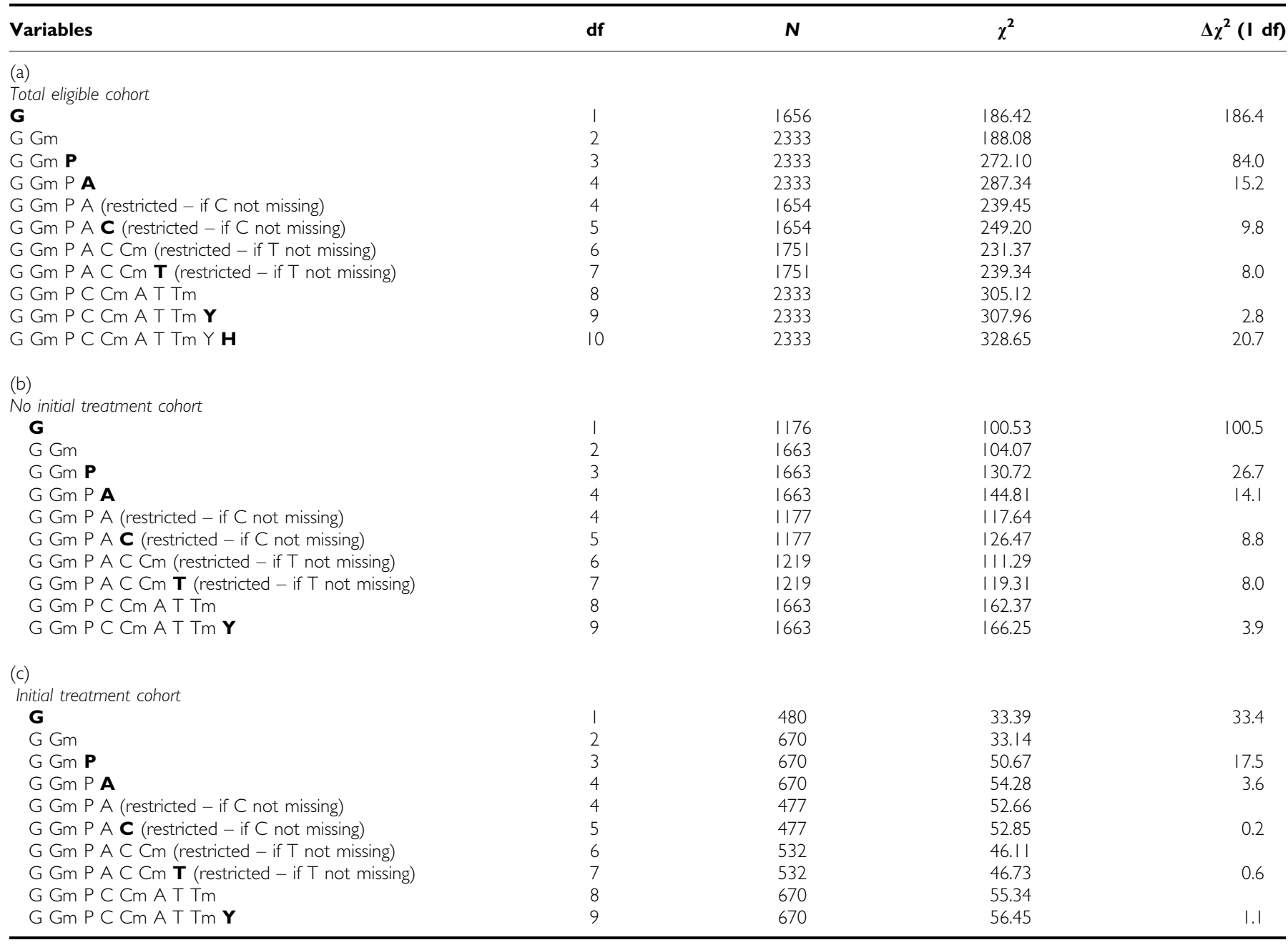

Investigators in participating regional cancer registries and hospital trusts are listed below:

Thames Cancer Registry: Henrik Møller ${ }^{*}$, Shirley Bell (deceased), K Linklater, J Ottey V Fisher; Ashford \& St Peter's, M Hall, N Harvey Hills; Barnet \& Chase Farm, H Reid; Brighton and Sussex, N Kirkham, P Thomas; Bromley, D Nurse; Dartford \& Gravesham, I Dickinson, P Thebe; East \& North Hertfordshire, D Hanbury, M Ali-Izzi; Eastbourne, C Moffatt; Epsom \& St Helier, M Bailey, L Temple; Essex Rivers Healthcare, W Aung, C. Booth; Frimley Park, B Montgomery, P Denham; Greenwich Healthcare, N Cetti, P Pinto; Guy's \& St Thomas's, A Chandra, T O'Brien; Hammersmith Hospitals, N Livni; Havering Hospitals, I Saeed; Hillingdon, F Barker, T Beaven; King's Healthcare, G Muir, Z Khan; Kingston, C Jameson; Lewisham, A Giles; Mayday Healthcare, N Arsanious, A Arnaout; The Medway, E Boye; Mid Essex Hospitals; Mid Kent, M Boyle; North West London Hospitals, M Jarmulowicz; Royal Free Hampstead, RJ Morgan, A Bates; St Bartholomew's and The Royal London Hospitals, F Chinegwundoh, RTD Oliver, D Berney; Royal Surrey County, S De Sanctis; Southend, M Chappell; St George's, London, R Kirby, C Corbishley; St Mary's, London, A Patel, M Walker; West Hertfordshire, J Crisp, W Riddle; Worthing \& Southlands Hospitals, J Grant.
Northern \& Yorkshire Cancer Registry \& Information Service: David Forman ${ }^{*}$, C Storer, C Bennett, C Spink; Airedale, I Appleyard, J O’Dowd; Hull \& East Yorkshire, J Hetherington, A MacDonald; The Leeds Teaching Hospitals, P Whelan, P Quirke, P Harnden.

Oxford Cancer Intelligence Unit: Monica Roche*, Sandra Edwards, S Bose, P Hall; Heatherwood \& Wexham Park, M Ali, O Karim; Milton Keynes, E Walker, S Jalloh; Northampton, M Miller, A Molyneux; Oxford Radcliffe, S Brewster, D Davies; Royal Berkshire \& Battle, P Malone, C McCormick; Stoke Mandeville, J Greenland, A Padel

Welsh Cancer Intelligence \& Surveillance Unit: John Steward*, Shelagh Reynolds, Lynda Roberts, Judith Adams; Ceredigion and Mid Wales, J Edwards, CGB Simpson; Conwy \& Denbighshire, A Dalton, V Srinivasan; NE Wales, A De Bolla, C Burdge; Gwent Healthcare, W Bowsher, M Rashid; Swansea, M Lucas, C O'Brien; Cardiff \& Vale, M Varma.

Scottish Cancer Registry: David Brewster ${ }^{*}$ The Lothian University Hospitals, J Royle, K Grigor; North Glasgow University Hospitals, D Kirk, A Milano, R Reid.

Merseyside \& Cheshire Cancer Registry: Lyn Williams ${ }^{*}$ R Iddenden; Royal Liverpool University Hospital, CS Foster, P Cornford.

Memorial Sloan Kettering Cancer Center: H Lilja*, S Eggener*. 